\title{
Mortality in acromegaly decreased in the last decade: a systematic review and meta-analysis
}

\section{F Bolfi' , A F Neves' ${ }^{1}$, C L Boguszewski² and V S Nunes-Nogueira'}

'Department of Internal Medicine, São Paulo State University/UNESP, Medical School, Sao Paulo, Brazil and ${ }^{2}$ Endocrine Division (SEMPR), Department of Internal Medicine, Federal University of Parana, Curitiba, Brazil
Correspondence should be addressed to V S Nunes-Nogueira Email

vania.nunes-nogueira@ unesp.br

\section{Dear Editor} of the European Journal of Endocrinology by Esposito et al. (1), we have decided to update the meta-analyses of our systematic review published last year (2), in which the above-mentioned study was included.

The corrected data have not changed our conclusions (Fig. 1). We reaffirm that in comparison with studies published before 2008, standardized mortality rate (SMR) in acromegaly decreased in the last decade, probably due to the most frequent use of somatostatin analogs as adjuvant therapy in patients not controlled with surgery (SMR before 2008: 1.76, 95\% CI: 1.52-2.04; SMR after 2008: 1.35, 95\% CI: 0.99-1.85 and SMR: 1.26,

95\% CI: 1.03-1.54, respectively, original and updated meta-analysis). All revised analysis and figures are available on request.

\section{Declaration of interest}

Cesar Boguszewski is an Associate Editor of European Journal of Endocrinology. Cesar Boguszewski was not involved in the review or editorial process for this paper, on which he is listed as an author. The other authors declare that there is no conflict of interest that could be perceived as prejudicing the impartiality of this article.

\section{Funding}

This research did not receive any specific grant from funding agencies in the public, commercial or not-for-profit sectors.
Published by Bioscientifica Ltd. 
SMR

Study or Subgroup IV, Random, $95 \% \mathrm{Cl}$ Year

SMR

1.2.1 Studies Published before 2008

Wright 1970

$1.89[1.44,2.49] 1970$

Alexander 1980

Nabarro 1987

Bengtsson 1988

$3.31[2.46,4.45] 1980$

Etxabe 1993

$1.26[0.94,1.69] 1987$

Bates 1993

$1.80[1.50,2.16] 1988$

Abosch 1998

$3.23[1.72,6.07] 1993$

$2.68[1.85,3.88] 1995$

Orme 1998

$1.28[0.88,1.86] 1998$

Shimatsu 1998

$1.60[1.44,1.78] 1998$

Swearingen 1998

$2.10[1.76,2.51] 1998$

$1.16[0.66,2.04] 1998$

Beauregard 2003

$2.14[1.34,3.42] 2003$

Arita 2003

$1.17[0.64,2.14] 2003$

Holdaway 2004

$2.70[2.13,3.42] 2004$

Biermasz 2004

$1.33[0.91,1.94] 2004$

Kauppinen-Mäkelin 2005

$1.16[0.85,1.58] 2005$

Trepp 2005

$1.34[0.77,2.33] 2005$

Bex 2007

$1.39[0.96,2.01] 2007$

Subtotal $(95 \% \mathrm{Cl})$

$1.76[1.52,2.04]$

Heterogeneity: $\mathrm{Tau}^{2}=0.06 ; \mathrm{Chi}^{2}=69.50, \mathrm{df}=16(\mathrm{P}<0.00001) ; \mathrm{I}^{2}=77 \%$

Test for overall effect: $Z=7.53$ ( $P<0.00001$ )

1.2.2 Studies Published after 2008

Sherlock $2009 \quad 1.69[1.45,1.97] 2009$

Wu 2010

$1.93[1.22,3.05] 2010$

Arosio 2012

Bogazi 2013

$1.15[0.90,1.47] 2012$

Colao 2014b

$0.70[0.45,1.09] 2013$

$2.01[1.59,2.54] 2014$

Mercado 2014

$0.76[0.50,1.16] 2014$

Varadhan 2016

$1.00[0.57,1.75] 2016$

Maione 2017

$1.05[0.77,1.43] 2017$

Esposito 2018

$1.33[1.17,1.52] 2018$

Subtotal $(95 \% \mathrm{Cl})$

$1.26[1.03,1.54]$

Heterogeneity: Tau $^{2}=0.07 ; \mathrm{Chi}^{2}=42.15, \mathrm{df}=8(\mathrm{P}<0.00001) ; \mathrm{I}^{2}=81 \%$

Test for overall effect: $Z=2.22(P=0.03)$

Total $(95 \% \mathrm{Cl})$

$1.56[1.38,1.77]$

Heterogeneity: $\operatorname{Tau}^{2}=0.07 ; \mathrm{Chi}^{2}=134.54, \mathrm{df}=25(\mathrm{P} \leq 0.00001) ; \mathrm{I}^{2}=81 \%$

Test for overall effect: $Z=7.00(\mathrm{P}<0.00001)$

Test for subaroup differences: $\mathrm{Chi}^{2}=6.93, \mathrm{df}=1(\mathrm{P}=0.008), \mathrm{I}^{2}=85.6 \%$

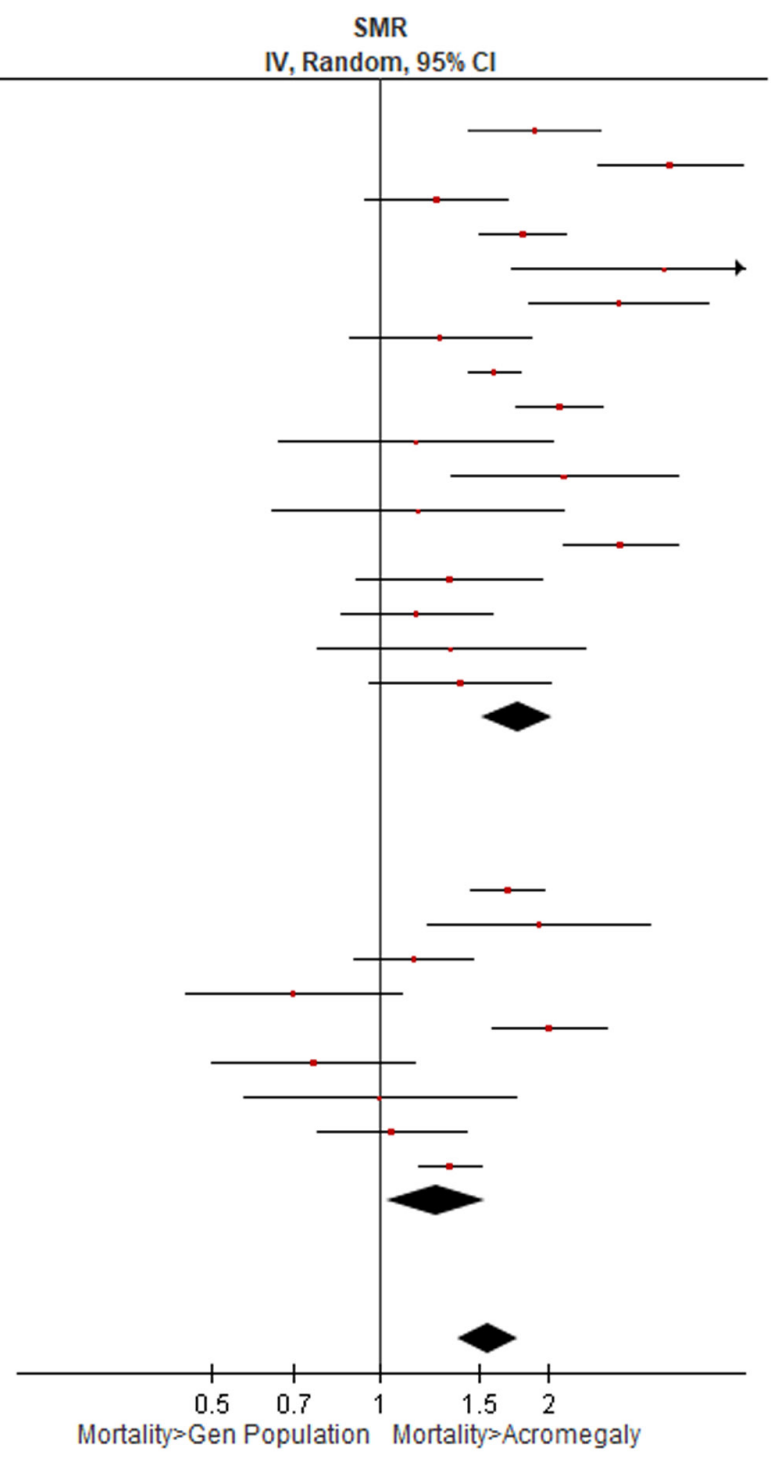

\section{Figure 1}

Revised meta-analysis of standardized mortality rate (SMR) in acromegaly from 26 studies, with subgroup analysis of the studies published before and after 2008. A full colour version of this figure is available at https://doi.org/10.1530/EJE-19-0509.

\section{Acknowledgement}

The authors thank Dr Daniel S Olsson for providing the data to update this manuscript.

\section{References}

1 Esposito D, Ragnarsson O, Granfeldt D, Marlow T, Johannsson G \& Olsson DS. Decreasing mortality and changes in treatment patterns in patients with acromegaly from a nationwide study. European Journal of Endocrinology $2019 \mathbf{1 7 8}$ X1-X3. (https://doi.org/10.1530/ EJE-18-0015e)

2 Bolfi F, Neves AF, Boguszewski CL \& Nunes-Nogueira VS. Mortality in acromegaly decreased in the last decade: a systematic review and meta-analysis. European Journal of Endocrinology 2018179 59-71. (https://doi.org/10.1530/EJE-18-0255) 